\title{
Políticas educativas y reforma estatal en la provincia de Córdoba, Argentina*
}

\author{
Ahumada, Jorge Nelson*
}

\section{Resumen}

El presente trabajo surge de dos líneas de investigaciones sobre la Políticas de Educación en la Provincia de Córdoba, Argentina. Se estudiaron los cambios en este campo de actuación del Estado, tanto las estrategias del gobierno, como de los actores relevantes, se estudió además la percepción sobre los cambios de los prestadores del servicio educativo y de los usuarios. Los objetivos más generales del programa de investigación tienden al logro de una caracterización de las formas y los límites que asume la gobernabilidad del sistema de gestión de políticas sociales y sus efectos sobre la orientación de las políticas de educación a nivel provincial. El análisis se ha desarrollado con base en la revisión de la legislación, información periodistica, entrevistas, grupos de discusión con los actores relevantes y aplicación de encuestas poblacionales por muestreo. El estudio se inició en 1991 y actualmente está en su etapa final. Se logró caracterizar el cambio del sistema de gestión que posibilitó incorporar las nuevas estrategias de racionalización en el servicio educativo, así como los elementos de la dinámica política que posibilitaron estos cambios.

Palabras clave: Estado de bienestar, políticas educativas, gobernabilidad, reforma del Estado, Argentina.

\section{Recibido: 99-10-15. Aceptado: 00-06-23}

- Una versión de este trabajo fue presentada en el XXII Congreso de Asociación Latinoamericana de Sociología (ALAS). Concepción. Chile. 1999. El trabajo es parte de los resultados de dos líneas de Investigación sobre la Crisis del Estado de Bienestar y la Racionalización de Políticas, y sobre los camblos ocurridos al interior de los campos de Salud y Educación en la década del 90, los mencionados estudios son dirigidos por el Master Carlos La Serna y se desarrollan desde el Area de Políticas Públicas del Instituto de Investigación y Formación en Administración Pública, Universidad Nacional de Córdoba.

** Magister en Administración Pública. Profesor de Teoría de la Administración Pública, Administración del Sector Público y Tecnología de Gestión Pública en las Universidades Nacionales de Villa María y Río IV (Provincia de Córdoba). Docente en la Maestría de Administración Pública de la Universidad Nacional de Cordoba e Investigadora del Instituto de Investigación y Formación en Administración Pública de la Universidad Nacional de Córdoba. E-Mail: Jahumada@ eco.uncor.edu. 


\section{Educational Policy and State Reform in the Cordova Province of Argentina}

\section{Abstract}

This research is the product of two lines of investigation as to educational policy in the Cordoba Province of Argentina. Changes in the area of State action, both governmental strategy and relevant actors in the process, are studied, as well as the perception of users as to the changes in the offer of educational services. The general objective of the research program is to characterize the forms and limitations assumed by the government in the development of social policies and its effect on educational policy at the provincial level. The analysis was developed through revision of legislation, journalistic information, interviews, group discussion with the relevant actors, and sample population surveys. The study began in 1991 and is presently in its final stages. The changes in the system under development were characterized which made possible the incorporation of new strategies of rationality in the offer of educational services, as well as elements of dynamic policy which make the changes possible.

Key words: Welfare state, educational policy, governability, state reform, Argentina.

\section{La Educación como Política de Estado en Argentina}

La dimensión de la problemática educativa para el Estado acepta diversas perspectivas que guardan relación directa con el tamaño de este Servicio. Una forma de abordarlo es identificar los destinatarios potenciales con lo cual se incluye a toda la población de un país cuya edad esté comprendida en el grupo etáreo que va desde los 3 años a los 30 años. Esta población representa, aproximadamente, el $50 \%$ de los habitantes de la mayoría de los países de Latinoamérica, pero en aquellos países que no realizaron la transición demográfica (países con población joven y alta tasa de natalidad) se extiende al $60 \%$ o más (Rama, 1994).

Además del volumen poblacional se plantean otros desafíos de magnitud equivalente, como la necesidad de cobertura geográfica en todo el territorio para garantizar accesibilidad, las diferencias biológicas y psicológicas entre los distintos subgrupos etáreos, la diversidad cultural por regiones $y / 0$ por clases sociales y sobre todo por la forma "mano de obra intensiva" en que el Servicio se presta con lo cual si el volumen de los destinatarios es grande también lo es el personal prestador. 
En Argentina durante la década del ' 60 , cuando se hallaba incorporado al sistema educativo el $85 \%$ de la población de 6 a 14 años de edad, comienzan a visualizarse inconvenientes en el financiamiento del sistema educativo. Este proceso conduciria durante el último gobierno de facto, y a posteriori, en el año 1992, a la transferencia de la mayor parte de las Escuelas Nacionales a las jurisdicciones provinciales.

La crisis socioeconómica que caracterizó la situación de Argentina durante los ochenta ${ }^{1}$ afectó al sistema educativo de diferente maneras, contribuyendo a que el Gobierno Local incorporase esta problemática a su agenda de cuestiones.

En nuestro pais y también en nuestra Provincia hay un ciclo escolar que es obligatorio, lo que implica la responsabilidad estatal en garantizar no sólo su cobertura financiera sino también atender toda la complejidad que antes sólo enunciamos. Fácilmente se puede argüir que el tamaño del problema guarda correspondencia con las dificultades que histó- ricamente ha presentado. Desde la impotencia crónica de los Estados para financiar el senvicio, hasta las diversas patologías burocráticas que "naturalmente" han formado parte del Aparato Educativo.

Sin embargo la trascendencia del sistema Educativo en la integración $\mathrm{Na}$ cional, como factor clave para el desarrollo Económico y Social y su papel fundante en la reproducción cultural de las sociedades es también largamente reconocido, no sólo es un ejercicio académico este reconocimiento sino sobre todo poblacional lo cual también es objeto de estudio de nuestra investigación ${ }^{2}$.

La importante cobertura social del Servicio Educativo incluye las diferencias propias de la población que atiende y que han generado en el tiempo una "segmentación" al interior del aparato educativo que atiende grupos sociales diferentes. La diferencia entre las escuelas Públicas y Privadas está centrada en la clientela que cada una atiende, más que en diferencias claras de calidad, el origen social es entonces un carácter distintivo de los establecimientos Educativos y salvo ex-

Entrada la década del 80 , la industria dejó de ser la principal fuente de empleo urbano en Córdoba, pasando el sector servicios a ocupar su lugar. La terciarización de la economía fue acompañada por una creciente intormalización de la fuerza laboral y por el incremento de la pobreza urbana. El denominado sector informal y cuasi-informal del mercado de trabajo creció de manera ininterrumpida, pasando desde el $30,7 \%$ de la fuerza laboral en 1974 al $37,7 \%$ en 1983. En la base de esta evolución estuvo el progresivo deterioro de la industria automotriz y con ella de la rama metalmecánica en general y una dinámica de las restantes ramas incapaz de generar un renovado impulso. Para una caracterización socio-económica y espacial de la Ciudad de Córdoba, La Serna, C. y Tecco, C.

2 Es abundante la bibliografía que desde diversas vertientes teóricas interpreta el fenómeno Educativo, sin embargo no hay negaciones de su trascendencia aŭn en propuestas extremas como las de lván liich, ver Tedesco 1986-1987, Parra et al 1986, Rama 1987, Nassif et al 1986. 
cepciones, los mecanismos de ingreso continúan reproduciendo los grupos educativos por "origen de clase"

Las presiones sobre el "Gasto Social" impactan también en el Financiamiento Educativo. El ajuste estructural ha encontrado grandes dificultades para operar linealmente en el sector Servicios al generar gran resistencia poblacional a estas restricciones. La demanda por estos "Salarios Indirectos" se aumenta en un momento histórico donde justamente es el Salario una de las Instituciones Bienestaristas que está en decadencia ${ }^{4}$. Los efectos de la "globalización" afectan de diversa manera al sector Servicios pero un mecanismo de gran potencial es la incorporación al interior del Estado de relaciones de mercado.

La tendencia progresiva de ubicar al mercado como "el gran asignador de recursos" pone en cuestión la esencia de los Servicios "Públicos" tal y como fueron concebidos históricamente en nuestro país, un ejemplo está dado por la Soberanía del Consumidor que es posible en el mercado de Bienes pero que en el caso de los Senvicios como Salud y Educación es dificilmente lograble por lo cual son Mercados Imperfectos por naturaleza (Katz, 1989).

Por otro lado en la producción de bienes la calidad se puede regular por el mercado pero en el Servicio Educativo el mercado acepta o rechaza al "producto" pero no al productor con lo cual el mercado sólo incide muy indirectamente en la calidad, ejemplo de esto es la baja relación existente entre permanencia en el sistema Educativo por un lado e inclusión y/o ascenso en el Mercado de Trabajo por otro. Esta correspondencia es mucho mayor entre origen social y mercado de trabajo (Girod, 1984).

A este respecto Germán Rama plantea que aún los jóvenes pertenecientes a sectores sociales de medios y altos ingresos tienen un futuro laboral incierto, porque la tendencia histórica a ocupar posiciones ocupacionales por adscripción comienza a deteriorarse ante la exigencia de logros competitivos (Rama, 1984), aquí también se puede observar un efecto de la globalización: la demanda del mercado laboral es de capacitación instrumental especializada que de ninguna manera puede brindar un sistema educativo construido en base a reproducción social cultural y capacitación en conocimientos básicos de los diversos desarrollos de la Ciencia y de la Técnica. La capacitación instrumental especializada implica tal diversidad que no puede ser cubierto por un sistema unificado por normas básicas, pero esta búsqueda puede implicar la pérdida de gran parte de sus

3 La función reproductora de la Escuela ha sido claramente descripta por diversos autores entre los que vale citar a Pierre Bourdieu, Basil Bernstein, Baudelot y Establet.

4 Para Robert Castel en el Estado de Bienestar hay un compromiso social donde el trabajo funciona como un régimen de empleo asegurando protección social, a esto denomina Castel "sociedad salarial", el trabajo ya no es regido totalmente por el mercado sino que la intervención estatal modera los riesgos. 
anteriores funciones (este riesgo está implícito en la actual reforma educativa en Argentina).

Esta breve perspectiva del Sistema Educativo permite plantear al menos dos interrogantes: qué efecto tendrán los cambios actuales y a qué factores obedecen los mismos?

La necesidad de legitimación del Aparato Estatal conduce necesariamente a la contradicción entre atender las necesidades poblacionales y atender a las presiones de equilibrio fiscal, esta contradicción se agudiza en períodos recesivos como el actual en los cuales al decir de Offe "lo necesario se hace imposible y lo imposible se hace necesario". Esta frase es ilustrativa de la actual encrucijada para el Estado y para el sistema educativo en particular: la educación debería aportar soluciones al desempleo facilitando el ingreso al mercado de trabajo y por otro lado se genera la necesidad de "capacitarse" para trabajar cuando el mercado de trabajo está tan restringido que no solamente dificulta la creación de nuevos puestos sino que además expulsa fuerza de trabajo.

Esta ecuación entre necesidades e imposibilidades muestra descarnadamente algunas contradicciones entre el Capital y el Trabajo, por ejemplo:

- Un distanciamiento cada vez mayor con el pleno empleo pero una inédita variedad de puestos de trabajo.

- Un desequilibrio en aumento, entre las crecientes necesidades de consumo y la decreciente capacidad económica de consumir.

Aquí es donde se espera de la Educación un resultado inalcanzable: suplir a la economía como factor de generación de empleo e ingresos. Esto podria ser denominado como aquello que Marx nombró como "fetichismo de las mercancias". Este importante concepto encierra una explicación antropológica de la propensión generalizada al consumo en nuestra sociedades capitalistas.

También el Servicio Educativo es consumido como mercancia y al decir de Adam Smith "los servicios perecen en el mismo instante de su realización ${ }^{n}$ con lo cual se diferencian de los bienes, pero al igual que éstos poseen cualidades construidas subjetivamente (asignarles un valor de cambio que no necesariamente se corresponde con el valor de uso). El discurso oficial sobre el Servicio Educativo muestra la capacidad asignada a la escuela de favorecer el ingreso al mercado laboral, sobre todo recientemente quienes diseñan los cambios afirman esta capacidad. Sin embargo lejos está la Educación de poder resolver el problema del empleo; sólo aporta condicionamientos al mercado de trabajo pero de ninguna manera es la causa de su expansión.

Por otro lado, la terciarización de la Economia ha generado una nueva oferta Educativa desde el sector privado, altamente lucrativa, que incorpora modernas técnicas de marketing y publicidad. Esta oferta se basa en la promesa de "proveer" de cualidades para ingresar $y$ ascender en el mercado laboral, así estas "imágenes de consumo" (Ewen, 1996) han permeado la sociedad y hay una nueva demanda social de capacitación laboral a la escuela Pública que esta no puede satisfacer y que cabria interrogarse si debe.

La función histórica de la escuela es su rol inclusivo en lo cultural pero secundariamente en lo económico, además 
la inclusión cultural es tan importante como la económica y es condición indispensable para la inclusión plena. En la etapa actual la expulsión de fuerza de trabajo está agudizando la exclusión de sectores estructuralmente pobres pero además está generando nuevos pobres (Kessler, 1995).

Las condiciones de marginalidad son también culturales por to cual es en este período en el que la función integradora de la escuela es trascendente, sin embargo es cuando está más debilitada para cumplir ese papel. Parte de la explicación de ese debilitamiento está en la diversificación de los procesos de socialización que antes eran resumidos en la escuela, pero también en un nuevo direccionamiento de la escuela hacia el mercado de trabajo lo cual le resta capacidad a su rol de promoción de valores comunes e ideales civicos, aspectos centrales en la inclusión cultural.

Europa es un buen ejemplo de cómo los logros en igualdad fueron mayores, via distribución del ingreso monetario por tributos progresivos y redistribución por las politicas sociales que los obtenidos por ampliación de oportunidades por la educación. La expansión de la educación en esos países tuvo más que ver con el propósito de asegurar la formación básica que se requería para cada etapa de desarrollo (mayor complejidad en la interacción social, mayores requerimientos de calificación de los recursos humanos) y la educación necesaria para que una parte de la población no quedara rezagada frente a la cultura promedio.

Como consecuencia lógica, la participación de los distintos estratos sociales en los distintos niveles educativos fue resultado de los cambios inducidos por la diferenciación técnica y social (que modificó la estructura de las ocupaciones y sus calificaciones) por los cambios en el consumo cultural (y por ende en los requerimientos educativos) y sólo marginalmente fue el resultado de una movilización social por la participación en la educación. Este es un claro ejemplo que muestra cómo es el desarrollo general el que plantea demandas al sector y no es el sector educativo el que define el desarrollo de un pais o región (Rama, 1994).

En América Latina este proceso se dio a la inversa, pues mientras el acceso a la educación en general y en especial a la media y superior tendió a la igualdad de oportunidades, y Argentina es un buen ejemplo con la masificación de las profesiones universitarias, la sociedad en su conjunto continuó siendo profundamente no igualitaria.

Este proceso se agrava a partir de los 80 con una espectacular concentración de la riqueza, que en países donde esta ya era la característica, profundizó las diferencias, pero en paises como el nuestro significó un vuelco en la igualdad de oportunidades sociales, esta concentración aún no se ha dado con toda intensidad en las oportunidades de acceso y permanencia en el sistema educativo. Tal vez aquí resida la explicación de las importantes presiones sociales a las que se ve sometido el sistema educativo, tal como mencionáramos al comentar las expectativas puestas en la educación como ampliador de oportunidades en el mercado laboral. (Un ejemplo: la ley de educación tiene un espiritu bienestarista y universalista contradictorio con las otras políticas del estado). 
La Educación como práctica social ha generado o estimulado el desarrollo de importantes disciplinas soporte, basta citar la pedagogía como patrón de referencia para la definición curricular y la Psicología evolutiva para fundamentar la didáctica (Rama, 1994). Otros ejemplos son la Lingüística, la Sociología, la Historia, etc, que incluso han iniciado verdaderas especialidades en sus respectivos ejercicios profesionales y desarrollos conceptuales dedicadas al ámbito Educativo. Este es un reflejo de la importancia socialmente asignada al hecho educacional, también lo es la creciente cobertura que tiene el servicio educativo como fenómeno mundial.

En uno de nuestros trabajos analizamos cómo los beneficios escolares son básicamente culturales, nuestro trabajo se basó en un estudio de campo en una zona de extrema pobreza y básicamente pudimos observar la valoración del sistema educativo como proveedor de "Educación" o sea como un fin en si mismo. La importancia de la escuela como escalón de ingreso al mercado laboral estaba totalmente desvalorizada por la población, teniendo así una percepción ajustada de lo que muestran importantes estudios internacionales (Gìrod, 1984).

Cabe preguntarse si la tendencia actual de los cambios Educativos tiene coherencia con los cambios sociales que están aconteciendo, si encierran una lógica voluntarista o por el contrario un sentido perverso al ofrecer cobertura de demandas que pertenecen al mercado laboral.

\section{La estructuración del campo de los servicios educativos: Estrategias, intereses y prácticas de los usuarios de los servicios de educación}

Kessler (1995) describe la percepción de los nuevos pobres respecto a su situación como beneficiarios del sistema educativo. Nos parece interesante tomar su estudio y comparar con los resultados de la presente investigación llevada adelante en grupos de pobres estructurales.

La problemática de la educación en los nuevos pobres es central ya que la crisis cuestiona profundamente sus proyectos de vida basados en el ascenso social. El sacrificio, la educación y el progreso se relacionaban íntimamente, hasta el punto de ser prácticamente vista como la única alternativa para el desarrollo material, social y cultural.

Esta visión, a partir de la situación de caída que viven estos grupos, se ha tornado en una ilusión. El empobrecimiento al que se hayan sometidos cuestiona profundamente estos valores por lo cual la cuestión "crisis de la educación" es una preocupación que aparece dominante frecuencia en estos sectores.

La crisis de la educación puede ser vista desde dos lugares, por un lado, el lugar de la educación dentro los proyectos de vida de las personas; y por el otro, la crisis del sistema educativo argentino. Con respecto al primer punto, como ya se señalara, hay una pérdida de confianza en las calificaciones profesionales como vía de ascenso social. Con respecto al segundo punto, el referido al sistema 
educativo argentino, la mayoría percibe un descenso del nivel educativo en la escuela pública. La causa central es percibida y atribuida por estos sectores al bajo presupuesto destinado a educación, que implica que el Estado no se hace más responsable de las nuevas generaciones.

Además de reclamar una mejora en la calidad de la enseñanza, las demandas se orientan a solicitar que la educación se adecue a las nuevas exigencias del mercado de trabajo. Sus exigencias corresponden con los tipos de servicios brindados en las escuelas privadas: "perciben 10 que los estudiosos han llamado "segmentación educativa", la existencia de escuelas de distintas calidades y temen por el futuro de sus hijos, que concurren a las que quedaron peor posicionadas; las escuelas públicas" (Kessler, 1995).

Para Bourdieu, el capital cultural puede manifestarse de dos maneras: como "estado institucionalizado" o como "estado incorporado" (Bourdieu, 1995). EI estado institucionalizado se refiere a los títulos obtenidos a través del sistema educativo que habilitan para el mercado de trabajo. El estado incorporado son las actitudes, inclinaciones que funcionan como principios de elección, percepción y reflexión. Ante la pérdida de la certeza de ascenso a través de los títulos, las demandas se han orientado más hacia el capital cultural como estado incorporado lo que, consideran la mayoría de los nuevos pobres, les permitirá a sus hijos una mejor integración social.

La escuela es valorada también por el capital social que aporta. La posibilidad de construir alli redes sociales sólidas es percibido como un beneficio importante el cual, en el pasado, no era tomado tan en cuenta.

Otro aspecto característico de la nueva pobreza es la circulación de sus niños por escuelas públicas y privadas. Se intenta con esto adecuar los bajos presupuestos familiares con las mejores ofertas que se puedan obtener: cambios de escuelas privadas a escuelas públicas, de escuelas privadas caras a otras de menor costo y también, en algunos casos, ante la percepción del deterioro de la escuela pública, aumento de los sacrificios de los padres, para enviar a los niños a escuelas privadas.

Una forma adicional de afrontar la crisis de la educación en los nuevos pobres reside en que gradualmente las familias van supliendo el rol tradicional de la escuela y tomando nuevas responsabilidades en la enseñanza de sus hijos: corrección de los cuadernos, completar los contenidos no vistos en las escuelas, horarios especiales de estudios, etc. Esta organización no está prevista sólo para los niños rezagados sino que sería una nueva modalidad generalizada para suplir los déficit en la formación de sus hijos y que no pueden ser satisfechos de otra manera por carecer de un nivel de ingre. sos suficiente.

\section{Educación y marginalidad urbana}

Las dificultades que la marginalidad genera a cualquier sistema educativo han sido largamente estudiados, desde los trabajos de Bourdieu y Passeron sobre la "barrera cultural" y los "códigos lingüísticos" de Basil Bernstein y los importantes trabajos desarrollados en América 
Latina sobre marginalidad urbana y educación (Parra 1986, Tedesco 1986 y Nassif 1986) por lo cual no redundaremos en ello, pero sí es de nuestro interés rastrear la utilidad esperable de la educación.

Desde los padres de los alumnos la percepción guarda una relación directa tanto con la experiencia que los padres tuvieron como alumnos, o con la falta de esta experiencia, como con su grado actual y pasado de marginalidad y exclusión del sistema de producción y consumo.

En este sentido la experiencia como alumno da a los padres una visión más valorizada de la educación como recurso para "defenderse en la vida" y a la vez las incorporaciones, aunque sea esporádicas, al mercado laboral dan un sentido más dirigido de la utilidad de las credenciales educativas pero también de su insuficiencia, "tener la primaria completa" es un piso indispensable pero no es suficiente, por lo contrario la condición de analfabetos o pobres extremos opera como un verdadero impedimento de "valoración".

Otro aspecto a contemplar es el grado de "calificación" que efectivamente produce la escuela y en este sentido está vastamente estudiado el fenómeno de una suerte de "complacencia" del sistema educativo con los alumnos de sectores marginales y de las entrevistas con docentes surge un objetivo prioritario de "socialización" en el sentido de inculcar hábitos básicos, sobre todo en la primera época de implementación del servicio educativo.

En las escuelas asentadas en zonas marginales de la Ciudad de Córdoba, nos preguntamos si la función de sociali- zación no tuvo tal grado de preeminencia que opacó las funciones estrictamente pedagógicas; pareciera, según se desprende de nuestros trabajos de campo, que actualmente hay una demanda más específica tanto de los padres como de las autoridades para mejorar la calidad $y$ los resultados escolares. De lo cual se observa que en una primera etapa los objetivos eran más básicos y que una vez cumplido se está avanzando en un proceso "más" educacional.

\section{Caída o límites de las expectativas?}

A diferencia de los nuevos pobres, los pobres estructurales parecen haber abandonado hace tiempo las expectativas de ascenso a partir de la educación. La educación para estos está ligada no al progreso sino a las posibilidades de integración $y$ asimilación en el sentido de acortar las distancias que los separan del resto de la sociedad y los alejan de los caminos de marginalidad: "les enseñan otra materias, otra cultura, salen con otra cultura..".

Se valora de los servicios educativos sus aspectos asistenciales materiales tales como guardapolvos, útiles, comida y aspectos a lo que hemos dado en llamar organizadores simbólicos tales como la disciplina y el control. El sistema educativo funciona en estos grupos como un organizador familiar alrededor del cual se establecen horarios, responsabilidades, plazos.

En este sentido la escuela cumple un rol de "periodizador" de la vida cotidiana estableciendo días escolares, de des- 
canso, feriados, vacaciones, que en otros sectores sociales a ese rol lo cumple otra instancia que es la inserción laboral. Así, en las familias cuyos jefes están insertos en el mercado laboral es el empleo el periodizador por excelencia y se complementa con la escuela que marca el ritmo de la vida cotidiana de los niños. De esta manera, a diferencia de lo que sucede en las otras clases sociales, la escuela no cumple un rol subalterno sino por el contrario, cumple un rol principal en el sentido que organiza la vida cotidiana de los niños y de los adultos, sobre todo de las madres.

Por ser el sistema educativo un servicio consumido en forma continua, a diferencia del sector salud que es utilizado en forma esporádica, logra un disciplinamiento importante alrededor de la actividad educativa misma.

Al privilegiar los usuarios los aspectos asistenciales y a los organizadores simbólicos no ocupa un lugar central la preocupación por los contenidos. Según la maestra: "los padres se quejan porque dejamos de poner la marcha de la bandera al entrar..." (maestra de la escuela).

Esta demanda es interpretada claramente por los maestros que incorporan una mirada social a la problemática educativa, hecho que se ve reflejado en la siguiente frase: "yo no puedo a un chiquito implementarle grandes métodos de enseñanza cuando está sufriendo un dolor por un latigazo en la espalda, yo tengo que subsanar muchas otras cosas para llegar a él, al intelecto..."(maestra de la escuela).

En estos comentarios está latente el objetivo de brindar otras oportunidades a los niños de estos sectores marginales, explícitamente fue uno de los objetivos de la política educativa Municipal "lograr ofrecer la igualdad de oportunidades mediante la satisfacción de las urgentes necesidades en materia de educación, alimentación y salud que presentan los sectores periféricos" (Carrizo, 1994).

Sin embargo, es un fenómeno comprobado el bajo impacto que tiene la educación en la movilidad social y para disminuir la desigualdad de las oportunidades sociales. Un conocido autor en Política Educativa dice "cuando una maestra se esfuerza por hacer progresar en cálculos aritméticos a un alumno que tiene dificultades en particular a causa de las paupérrimas condiciones de su familia, la tarea es difícil, pero clara. Ahora bien, qué puede hacer esa educadora o el sistema docente en su conjunto, para controlar los mecanismos que determinan la carrera futura de ese alumno o de cualquier otro?" (Girod, 1984). Esta frase muestra el eje del debate sobre el impacto del sistema educativo como promotor de oportunidades frente a otras variables como origen social y mercado laboral.

Así, la ilusión de ubicar a la educación en un rol preponderante en el desarrollo económico ha empalidecido a la luz de los resultados obtenidos y este hecho es percibido claramente tanto por los padres de los alumnos como por los docentes: "algunos chicos, alumnos nuestros, excelentes, inteligentes, que llegan a los 14,15 años y se dedican a robar porque no pueden conseguir trabajo..." "Al terminar la escuela primaria el chico no tiene otra salida"...(maestra de la escuela).

Sobre este mismo fenómeno es posible hacer distintas miradas. Por un lado, 
hay un intento desesperado de superar el limite de la escuela primaria, que es la actual línea de corte de la oferta educativa municipal. Por otro lado, también hay un registro que la escuela secundaria es condición necesaria pero no suficiente para romper los "designios del origen social". Al percibir esta contradicción los dirigentes barriales demandan dramáticamente la escuela secundaria y la capacitación en oficios, lo cual también ha sido registrado como indispensable por los docentes. Sin embargo, la mayoría de los entrevistados acepta este límite como algo natural.

En este mismo sentido, se puede explicar la separación que establecen los entrevistados, entre educación e inserción laboral, quitando la tradicional vinculación entre ambos hechos. (una frase tradicional podría ser "hay que estudiar para no tener que trabajar como un burro" y una frase actual "de nada sirve estudiar porque no hay trabajo"). Atribuimos este registro a una correspondencia con la realidad por un lado, pero también a un proceso adaptativo al fracaso sistemático en la inserción laboral, adaptación que aparece como una visión fatalista y naturalizada del fracaso, lo que hemos denominado como "identificación melancólica", la cual opera como adaptación por cuanto provee una explicación causal a la imposibilidad de cambio y esta explicación se termina poniendo en el mundo conocido, lo propio, lo interno, lo cercano. "Esto nos pasa por ser pobres" es una frase representativa.

Al igual que los nuevos pobres, los sectores analizados perciben el fenómeno de la segmentación educativa, sin embargo adoptan conductas diferentes, ya que perciben a las escuelas mejor posicionadas como inaccesibles, autoexcluyéndose de las mismas.

En esta visión, uno de los mecanismos racionalizadores de la gestión escolar es la búsqueda de la participación de los padres en la enseñanza, lo cual es percibido por el lado de los usuarios como un medio para desentenderse del rol tradicionalmente asignado: "las maestras nos tiran la responsabilidad a nosotras, $y$ para qué están ellas?".

Interpretamos este hecho como una tendencia a la depositación masiva del niño en la escuela lo cual surge por claros elementos objetivos relacionados con el analfabetismo, con el número de hijos, con la falta de hábitos en este sentido.

Asistimos a otra evidencia más de que aún cuando las intenciones subjetivas de los maestros son acercar a la familia a la escuela (formar la comunidad educativa) hecho en sí mismo altamente positivo, las consecuencias son el rechazo por parte de los beneficiarios que interpretan este requerimiento como otra forma más de abandono, rechazo que se explica por la impotencia para desempeñar roles más activos en general, roles activos en terrenos desconocidos, en particular el ámbito de la educación. Otra aspecto relevante es la relación causal que se establece entre ignorancia y pobreza, siendo para ellos el primer factor causa del segundo.

\section{La línea de corte}

Amartya Sen ha renovado el debate sobre la pobreza incorporando una rica discusión sobre las visiones técnicas a la condición de pobre, una visión 
absolutista le otorga caracteres identificatorios que van más allá del contexto y una visión relativa alude a la condición de pobre en tanto es sobre determinada por el contexto 5 .

Este debate nos es de gran utilidad por cuanto nos permite interrogar a la política Municipal sobre el tratamiento dado al tema de la pobreza y cómo ha sido percibido por los usuarios. No cabe duda sobre la direccionalidad de los Servicios Educativos hacia sectores que claramente puedan ser identificados como pobres, aunque en el nivel discursivo hay un cierto "universalismo" es clara la selectividad en la dirección de los servicios.

Ahora bien la estrategia priorizaba una visión transformadora de la pobreza o una visión asistencial sobre la misma? Creemos que en el nivel de los prestadores el "campo de servicios" tiene una perspectiva predominante de transformación en el sentido de mejora de las condiciones de vida, pero no en el sentido de cambio de las perspectivas de vida. Los docentes identifican como logros la incorporación de valores sociales y de convivencia familiar, sin embargo esta incorporación no es identificada por los docentes como valores de tal magnitud que posibiliten el cambio del "destino" de los usua- rios, pues la visión de futuro es vista frecuentemente como una repetición del presente "no les queda otra opción que robar".

En este sentido los maestros reproducen la visión fatalista sobre el futuro de los usuarios que estos mismos portan como representación de la vida (identificación melancólica).

Podría argumentarse que en tanto la visión sobre el resultado de los servicios es sólo de mejora de algunos aspectos de la vida (como la satisfacción de algunas necesidades), es una perspectiva asistencial a la pobreza; sin embargo los intereses puestos de manifiesto por los maestros exceden largamente una visión asistencialista y de hecho incorporan intereses de compartir e inculcar sus propios valores de clase como la cultura del esfuerzo, la previsión de la composición de la familia, la riqueza de matices de la vida cotidiana en oposición a la monotonía u opacidad de vidas grises y en general un sentido de la vida ligado estrechamente a la capacidad de acumulación (en el sentido que Bourdieu otorga a este término): no perder el tiempo, ganar dinero, conseguir trabajo, etc.

Es esta una lógica inevitable en el contacto cotidiano entre prestadores y

5 Sen (1984) propone que la pérdida o carencia de capacidades es un hecho absoluto de identificación de pobreza y a su vez se vincula en forma relativa con las carencias de bienes, ingresos y recursos. Esta discusión pone en entre dicho indicadores tales como "línea de pobreza" y "necesidades básicas insatisfechas"; el primer indicador alude a la capacidad de producir ingresos y consumo mientras que el segundo alude a la satisfacción de necesidades definidas previamente o de acuerdo a Boltvinik (1990) el primero es un indicador útil para el enfoque de la Políticas Económicas (consumo corriente) mientras que el segundo es un enfoque de las políticas sociales (consumo de servicios). 
usuarios que muestra que toda práctica técnica lleva implícita una valoración ideológica que trasciende el sentido originario del servicio y que en los casos de servicios en y a sectores marginales la carga ideológica en la valoración de la forma de vida es una parte de estos, que seguramente ocupa tanto o más interés del lado de los docentes que la currícula educativa misma.

\section{Los riesgos de las estrategias de racionalización}

Los temas anteriormente planteados deben ser investigados, no solo desde la perspectiva de los servicios, sino también de los usuarios. Entendemos que de ello depende la posibilidad de obtener una visión más comprensiva sobre el impacto real que están teniendo las estrategias racionalizadoras en el campo de las políticas sociales.

Especialmente porque posibilitan conocer los cambios que también se están produciendo en las formas en que se consumen los servicios, ya sea porque obedezcan a estrategias de resistencia a las innovaciones producidas por el sistema político administrativo $o$ a estrategias adaptativas frente a los cambios $y$, por otro lado, porque permitiría una mejor información acerca de la eficacia de los programas.

En el nivel del consumo propiamente dicho, los servicios han impuesto formas de utilización que se han construido históricamente como visiones legítimas y comportamientos esperados, construcción en la que han intervenido dos actores privilegiados: los prestadores de servicios y los usuarios de los mismos.
Esta relación implica una forma de dominación donde se esperaba de los alumnos pasividad en el desempeño de su rol de usuario, esta era la modalidad en que la dominación era ejercida.

Esta modalidad es la que actualmente está en entredicho pues por efecto de las estrategias de racionalización los servicios intentan imponer vías distintas de consumo o nuevas conductas en aquellos aspectos de la vida cotidiana vinculados directamente al servicio, nos referimos al pedido de mayor protagonismo y participación de los padres en el proceso de enseñanza aprendizaje, todo lo cual nos lleva a preguntarnos si:

Es posible lograr cambios en los hábitos construidos históricamente como pasivos hacia nuevos hábitos activos, sin generar un nivel de conflictividad tal que cuestione la esencia de los servicios?

Desde esta perspectiva las estrategias de racionalización son sometidas a la mirada sobre la influencia o interferencia que producen en el proceso de legitimación política, así las contradicciones como promoción y asistencia; bajo nivel de complejidad y alto nivel de complejidad; eje en to pedagógico o en la capacitación de oficios, contención áulica o contención social, son pares antagónicos que no solamente muestran oposiciones sino la conflictividad contenida en la transición que generan los procesos racionalizadores del sistema político administrativo.

\section{Las Imágenes Societales sobre la Educación}

En nuestra investigación, nos ha preocupado la percepción poblacional sobre los Servicios Públicos de Salud y 
Educación. En la primera y segunda eta$\mathrm{pa}$, la problemática de los cambios en el Estado y la Legitimidad social de los mismos fue un orientador importante. En la tercera etapa, de caracterización de las percepciones poblacionales, el eje es un elemento surgido de las dos etapas previas: el nuevo consenso ${ }^{6}$.

Cabe interrogarse sobre las formas, que debió asumir la acción estatal en América Latina para mantener la integración social; y en esta perspectiva pueden explicarse los regímenes autoritarios como formas extremas surgidas de la necesidad de mantener la cohesión social.

La etapa actual requiere de grandes esfuerzos para lograr legitimidad en la acción gubernamental, y representa un desafio a las ciencias sociales develar las estrategias mediante las cuales se busca lograr consenso social y/o arreglos institucionales para resolver, en el plano politico-cultural, la contradicción entre expectativas sociales de incorporación a la distribución de la riqueza con disminución en el tamaño del Mercado de Trabajo, por

Norberto Bobbio define el consenso como la existencia de un acuerdo entre los miembros de una unidad social acerca de principios, valores, normas y respecto de la deseabilidad de ciertos objetivos de la comunidad y de los medios aptos para lograrlos. El consenso se evidencia, por lo tanto, en la existencia de creencias que son más o menos ampliamente compartidas por los miembros de una sociedad. Dada la variedad de fenómenos sobre los cuales puede o no haber acuerdo y dada la intensidad de la adhesión a las distintas creencias, es improbable un consenso total aún en unidades sociales mínimas y es impensable en sociedades complejas, por ello el consenso se entiende en un sentido gradualista y no de presencia o ausencia. Claus Offe (1995) interpreta que la formación del consenso en el Estado Bienestarista se sostuvo en el llamado "síndrome productivista", los supuestos de este síndrome están centrados en la noción de que producción y productividad son deseables tanto individual como colectivamente. Los cinco supuestos productivistas son : la familia como institución, un mercado de trabajo inclusivo, el sistema de intermediación de las negociaciones entre los actores colectivos, la efectividad de la seguridad social y de la asistencia social en la cobertura de todas las categorias sociales y sustantivas de necesidad y riesgo y el consenso que sustenta este conjunto de arreglos institucionales. Estos supuestos se hallan cuestionados en las sociedades industriales avanzadas a partir de la década del 70 , y aún más por las recientes tendencias de los cambios económicos y sociales. Por ello, actualmente, son más dificiles de aceptar como válidos y como representaciones fidedignas de la realidad social y económica en las sociedades industrialmente avanzadas. Para O'Donnell en América Latina y especiaimente en nuestro país este sindrome productivista no tuvo el desarrollo que logró en los paises industriales avanzados en la década del 50 y del 60 . La forma en que el Estado Bienestarista se desarrolló en nuestra sociedad, correspondía a una gran coherencia en el plano económico macro y de acuerdo a los periodos respondió a alianzas de intereses económicos nacionales o internacionales. Cabe mencionar que esta coherencia al interior de la dinámica económica no guardó correspondencia con la dinámica social de contexto. Ejemplo de este hecho es la progresiva, continua y sostenida inclusión de sectores poblacionales en el servicio educativo público y la no inclusión de algunos de estos sectores en la producción económica (inclusión educativa con exclusión social). 
un lado (necesidades del campo productivo) y la disminución de la actuación Estatal via Servicios (necesidades del campo fiscal) por otro.

\section{Educación y desarrollo}

En las tensiones descriptas, la Educación juega un rol importante pues tradicionalmente funcionó como un igualador de oportunidades y aunque esta representación social está en decadencia, hay importantes motivos de integración económica y no económica que sostienen la demanda de todos los estratos sociales sobre el sector educacional. La demanda de los sectores más desfavorecidos es de integración cultural (no económica) y priorizan el acceso educacional como una forma de mantener o lograr generacionalmente una determinada "visión del mundo", propia de los estratos sociales medios y superiores.

En los sectores de pobreza estructural la demanda educativa funciona como un nuevo derecho adquirido y de alli su defensa, en los llamados "nuevos pobres" la educación mantiene un nexo con el anterior capital social y contiene una expectativa de progreso futuro al mediano plazo. En los sectores insertos plenamente en el sector productivo es un requisito para mantenerse en él y en los sectores más acomodados de la sociedad el conocimiento tecnológico y las destrezas necesarias son indispensables para entender la lógica productiva de un sistema internacionalizado.

Diversos autores han estudiado las correspondencias entre Educación y Desarrollo; desde las más distintas posiciones se acepta esta correspondencia, ya sea ubicando al sistema educativo en una misión univoca o en escenarios cambiantes y contradictorios.

Incluso hay importantes investigaciones que han estudiado el aporte de la educación al desarrollo, desde su función de construcción y fortalecimiento de la Nación ${ }^{7}$ hasta la formación de Recursos Humanos aptos para incluirse en sistemas productivos en expansión. Tenti analiza la función educativa en relación a la construcción de ciudadanía, "En la Argentina al igual que en la gran mayoría de los países de América Latina el Estado tuvo que ser educador para constituirse nacional, formando a los

7 En Argentina algunos trabajos importantes son E. Tenti 89, Tedesco 86. Para América Latina vale citar el importante estudio que constituyó el proyecto "Desarrollo y Educación en América Latina y el Caribe", realizado entre 1976 y 1981 . Proyecto finaciado por la UNESCO, CEPAL Y PNUD. La coordinación general estuvo a cargo de Germán W. Rama y participaron importantes investigadores del campo educativo como J.C. Tedesco, J. Rivero Herrera, R. Parra y R. Nassif entre otros. Hay varias publicaciones de los resultados del proyecto editados por Kapelusz, y son los textos de dicha editorial citados en el presente trabajo. Una importante autora brasilera que trabaja la temática es Paiva Vanilda 92. 
ciudadanos en sujetos de una nueva forma de vida social y política" ${ }^{8}$.

La utilidad de caracterizar el proceso educativo en nuestro pais, consiste en facilitar la identificación y explicación de orientaciones comunes de la política general y de la política educativa. Germán Rama (1986) comenta al respecto que hay tantos proyectos educativos como proyectos de país. Hay una imagen societal que se desea construir, la búsqueda de esta construcción es integrada y coherente en aquellos grupos con mayor conciencia de su papel histórico ${ }^{9}$.

\section{La Racionalización del Sistema Educativo}

En el caso de Educación, al igual que las otras políticas sociales, los cambios han estado directamente vinculados a la crisis fiscal y la legitimidad de los mismos se vincula a la necesidad de ordenamiento económico de las cuentas del Estado; de aqui surge una hipotética correspondencia entre restricción y consenso.

En las dos etapas anteriores de esta investigación hemos abordado la relación entre crisis fiscal y aciones de ra-

El valor social creciente otorgado a la educación, en nuestro país se inicia masivamente en 1880; desde aquel momento se puede observar una tendencia al crecimiento presupuestario de los programas educativos, el interés político del Area educativa también tuvo una presencla creciente en la agenda política del país. Estos hechos se pueden interpretar a la luz del fenómeno de la masividad del acceso escolar. En nuestro país la accesibilidad poblacional a la educación ocurrió varias décadas antes que a los Servicios Públicos de Salud (en este caso el momento inicial de acceso masivo se puede situar a mediados de la década de 1940). En un trabajo sobre políticas sociales y ajuste tres autoras Argentinas describen tres momentos en la formación del Sistema Educativo Argentino "a. constitución del Sistema Estatal de Educación (1880-1930); b. consolidación del Sistema Educativo (1930-1960) y c. fragmentación y deterioro del Sistema Educativo (1960 a la actualidad). Estos momentos guardan correspondencia con cambios ocurridos en el campo educativo que tienen una coherencia interna , entendible desde la perspectiva de orientación general que asumia el país en cada período. Los cambios son de tipo legal: el encuadre político-cultural de la educación tuvo una particularidad en cada uno de estos períodos; en el primero se legaliza el carácter púbtico y laico de la educación, en el segundo periodo la diversíficación educativa y la separación entre educación común y especializada. En el tercer período el eje orientador es la subsidiaridad del Estado en materia de educación tanto en su versión desarrollista como en la versión neoliberal (Grassi, et al).

9 Este autor caracteriza cuatro estilos educativos: a. Tradicional, b. de Modernización social, c. de Participación cultural, d. Tecnocrático, e. de Congelación política. Si bien esta caracterización puede considerarse como inacabada, tal como su autor explicita, tiene la utilidad de facilitar la identificación de estrategias educativas y su correspondencia con estrategias político-culturales. Nos interesa retomar los dos últimos estilos, por cuanto ellos contienen importantes elementos de comprensión del periodo actual en nuestro pais. Si bien el estilo tecnocrático y de congelación política, fue desarrollado por el autor pensando en otros momentos históricos (en nuestro pais el desarrollismo y procesos militares) las dimensiones 
cionalización (administrativo-organizacional y de coberturas), también hemos tomado los trabajos de Claus Offe (1990/1992) quien provee de una explicación político cultural para entender el soporte social de la nueva estructura Económica Internacional y su correlato en el ordenamiento social interno de cada país.

En América Latina y en nuestro pais, especiaimente los cambios en la estructura económica y en la dinámica social han sido relevantes. La orientación general en el campo de lo público muestra una evidente retracción estatal en el financiamiento, prestación o regulación de servicios públicos.

En el campo Educativo este fenómeno ha sido particularmente llamativo $y$ su inicio puede rastrearse claramente desde la década de 1980 con la transferencia de Servicios Educativos Nacionales a las Provincias y continúa con la progresiva orientación a la racionalización Administrativo-Organizacional y de Cobertura $^{10}$.
Una autora Brasilera, Vanilda Paiva, sitúa en el debate a la Educación como el "núcleo inicial del Estado de Bienestar", y esta historización en nuestro país se puede rastrear hasta el siglo pasado, explicación central de las resistencias masivas que generan los continuados embates para modificar la orientación histórica del Servicio Educativo (Paiva, 1992).

Si bien esta autora reconoce los desarrollos teóricos sobre la función histórica del Sistema Educativo en la Reproducción Social, de autores como Pierre Bourdieu o Basil Bernstein, discute con ellos sobre el rol educativo como igualador de oportunidades.

El planteo se centra en lo siguiente "En épocas de expansión económica y de pleno empleo, el sistema educativo, al contribuir a la reproducción ampliada del sistema, contribuye también a la democratización que se da en el interior de tendencias generales. Cuyo efecto en la posguerra fue vincular las oportunidades de la educación con las oportunidades de movilidad vertical en un sistema de ocu-

que utilizan y las variables empiricas que contienen estos dos estilos coinciden con aspectos de la realidad actual. Vale citar para el estilo tecnocrático que su estrategia educativa prioritaria está limitada a la preparación funcional y estratificada de los recursos humanos, en algunos casos ideológicamente despolitizados.

10 Un aporte teórico en este sentido es el de Claus Offe, ver "Contradicciones en el Estado del Bienestar" y "La Sociedad del Trabajo". En esta vertiente teórica y en nuestro país se pueden citar entre otros a Alberto Minujin, Rubén Lo Vuolo y Alberto Barbeito. En nuestra Provincia el Instituto de Investigación y Formación en Administración Pública tiene programas de investigación con esta orientación, el presente trabajo es uno de ellos, que están reflejados en parte en la publicación Administración Pública y Sociedad, por ejemplo los trabajos Carlos La Serna. Una interesante caracterización de la orientación general del Sistema Educativo actual en nuestro país ha sido desarrollada por dos prestigiados autores del campo educativo, Norma Paviglianiti y Diego Márquez, quienes básicamente identifican relaciones entre formas y 
pación y expansión económica. Las tendencias dominantes en la última década no van más en esta dirección, especialmente en la medida en que el terciario dejó de ser fuente de expansión del empleo. $Y$ en la medida en que la sociedad se petrifica en sus clases sociales y sus estamentos, el sistema educativo pasa a tener una función democratizante muy reducida" (Paiva, 1992).

Este planteo es de gran interés para entender la resolución del conflicto entre demanda poblacional creciente sobre el senicio educativo y reorientaciones de oferta que implican restricciones de acceso, ya sea por disminución de la variedad de oferta (Racionalización de Cobertura) o disminución de cantidad de Oferta (Racionalización Administrativo Organizacional).

La demanda poblacional creciente funcionó, en América Latina, como motor de una expansión educativa cuantitativa concentrada en los niveles medios y superior, aún en países donde el analfabetismo juvenil seguía siendo el problema principal. Esta dimensión poblacional de la dinámica del campo educativo ha sido descripta claramente y se ha observado repetidamente que "la expansión de la cobertura educativa habia promovido una explosión de las expectativas sociales imposible de satisfacer, dada la incongruencia entre el pronunciado incremento de los niveles educativos y la mucha más lenta expansión de las posiciones sociales medias y superiores....Se había producido una "devaluación de las credenciales educativas y disminuyó el aporte real de la educación al aporte económico y social"11.

Sin embargo, la demanda poblacional continúa creciendo hasta la actualidad y a los intensos requerimientos de los sectores medios urbanos, se agregaron las más modestas demandas de educación básica de la población rural que requirió escuelas primarias para hacer viable la incorporación de las nuevas generaciones a las sociedades urbanas. Esta tendencia generó contradicciones como la inclusión educativa de sectores sociales excluidos económicamente. En este contexto de demanda creciente se inscriben los cambios actuales instrumentados desde el Estado que merced a la crisis fiscal necesita racionalizar el Sistema y sus costos.

Este conflicto entre demanda creciente y restricciones de oferta se eviden-

contenidos de la Política Educativa Nacional y estrategias de ordenamiento económico interno y reacomodamiento internacional.

11 En cuanto a las restricciones de acceso, nuestra provincia sigue una tendencia nacional e internacional, la Racionalización de Cobertura se observa sobre todo en el nivel Primario (ejemplo la nuclearización Educativa, la organización de la matrícula escolar por radios geográficos y un mínimo de alumnos por grado). La racionalización AdministrativoOrganizacional se observa en los niveles Pre-primario, Secundario y Terclario (Ejemplo el cierre de establecimientos o el cambio de oferta educativa, promovido por el diferenciado perfil que se exige a cada establecimiento), (La Serna, 1999). 
cia en diversos escenarios, sin embargo y contradictoriamente hay aceptación pasiva de una responsabilidad menor del Estado en todos los Campos de su actuación.

Creemos que esta puede ser una encrucijada para entender futuros escenarios de conflicto, el planteo de Paiva orienta hacia la comprensión de una incipiente disminución del interés social por la Educación, pues la dinámica interna del mercado de trabajo es cada vez más refractaria a la estrategia educativa de formación de recursos humanos ${ }^{12}$.

\section{El campo Educativo y el Ajuste Estructural}

Pese a la deteriorada valoración educativa, desde una perspectiva Política Cultural vale el interrogante sobre:

Cómo la restricción en variedad y cantidad en el acceso a Servicios Públicos en General y Educativos en particular, ha podido ser aceptada?

Una particular convergencia histórica puede permitir interpretar que hay una base de consenso sobre el ajuste ${ }^{13}$.
Si bien una interpretación de este tipo es plausible, no necesariamente lo es una explicación en este sentido, asi puede interrogarse la misma noción de consenso como un concepto límite cuando hay una aparente contradicción entre racionalidad y realidad (Navarro, 1995).

Hemos planteado dos elementos que consideramos de interés para el debate, en primer lugar, pese a la disminución de su rol de igualador de oportunidades, se sigue demandando masivamente el Servicio Educativo por funciones que hemos descripto como de índole económica y socio-cultural. En segundo lugar, si esta demanda continúa siendo masiva, cómo se ha hecho posible la aceptación social de las restricciones impuestas a la oferta educativa por necesidades de racionalidad fiscal?

Creemos que las respuestas a estos interrogantes están en el mismo Sistema Educativo. Todos o la gran mayoría de los sujetos que componen los distintos Actores Sociales agregados del campo educativo, han participado del servicio Educativo y es previsible que cuanto mayor importancia tenga un determinado ac-

12 Incluso la formación técnica especializada se está dando en forma progresiva fuera del ámbito estatal y merced al cambio tecnológico hay una polarización creciente en la fuerza de trabajo: a: el trabajador con baja calificación para empleo rutinizado, altamente normatizado y con precarización laboral, que mantiene su condición ocupacional sólo en el período activo de la Economía y $b$ : el trabajador calificado con manejo fluido del lenguaje informático, con mayor tiempo real de ocupación pero con gran movilidad en las distintas fuentes laborales. Para ambos casos la escuela tradicional no es útil, para el primer caso es demasiado y para el segundo es demasiado poco (Paiva).

13 Reviste especial interés mencionar que ha llamado la atención de diversos autores el comportamiento poblacional ante "el ajuste". Un autor Cordobés, (Navarro, 1995), ha desarrollado una importante revisión sobre el debate alrededor de esta "tolerancia popular al ajuste económico" y aunque no incluiremos mayores precisiones sobre el particular, si vale citar 
tor en una organización o institución, mayor habrá sido su permanencia en el sistema educativo.

Desde esta perspectiva la posición de los actores no puede ser independiente de su pertenencia a una visión dominante del mundo que transmite el sistema educativo. Por ello es más previsible que los cambios en el campo educativo respondan a una fuerte tendencia endógena, esto es, ocurren en gran parte desde el interior del mismo. El sistema tiene una gran capacidad para resistir los embates externos al ser un campo que construye y reproduce representaciones, valores, intereses y estrategias en el conjunto de la sociedad.

Este enfoque ayuda a entender que la necesidad de racionalidad por imperio de la crisis fiscal, ha podido penetrar lentamente en el sector educativo porque previamente tuvo un cierto grado de aceptación en su interior; pues si algo caracteriza al campo educativo es que sus integrantes son vulnerables frente a los argumentos técnicos. Es el sistema educativo el principal productor y reproductor de conocimientos técnico-científicos y la necesidad del ajuste fiscal se basa en este tipo de argumentos, despolitizándolos.

Pierre Bourdieu recrea una importante producción sobre la objetivación de la realidad, aspectos de su obra que aportan a una probable explicación sobre la correspondencia entre restricción y consenso, "La violencia simbólica es, para expresarme de la manera más sencilla posible, aquella forma de violencia que se ejerce sobre un agente social con la anuencia de éste... En términos más estrictos los agentes sociales son agentes conscientes que aunque estén sometidos a determinismos, contribuyen a producir la eficacia de aquello que los determina, en la medida en que ellos estructuran lo

una observación por demás llamativa "Un acertijo recorre a la Sociología Política: la tolerancia popular a los procesos de ajuste económico..... Hoy casi no sorprende la adhesión popular a Menem, Fujimori, Zedillo aunque cada uno de estos casos, en distinta medida, representen reales desafios de inteligibilidad......... Hasta el momento no se dispone de un adecuado marco conceptual para analizar este tipo de proceso; las principales revisiones sobre la reciente literatura han constatado un déficit teórico." El trabajo citado es una interesante revisión sobre este debate y una crítica sobre el mismo desde la teoría de los juegos. El autor identifica al menos seis posiciones teóricas sobre la tolerancia ante el ajuste, A) Consenso basado en las expectativas sobre el futuro, ubicando en esta perspectiva a autores como Hirschman y Przeworsky, b) Consenso basado en la heterogeneidad social, Claus Offe; C) La aceptación del credo Neoliberal por parte de las poblaciones (cambio de valores, miedo a la hiperinflación adhesión masiva a la estabilidad), Minujin y Kessler, Mora y Araujo; D) La "manipulación gubernamental" Acuña y Smith; E) El consenso del miedo "fuga hacia adelante" (Administración del Capital Político y salida única); Palermo y Torre F) La "anomia social"y la "crisis de representación", Cavarozzi, O'Donell, Portantiero y Zermeño. Por último el autor esboza una Hipótesis sobre los cambios en la cultura política y social como puntas explicativas de la tolerancia ante el ajuste. 
que los determina. El efecto de dominación casi siempre surge durante los ajustes entre los determinantes y las categorías de percepción que los constituyen como tales $^{\text {14 }}$ (Bourdieu, 1995/1997).

\section{Percepciones sobre la Reforma Educativa en Córdoba}

A partir de lo desarrollado sobre las características del consenso histórico y de las transformaciones que en el campo educativo se están operando, el análisis orientó hacia la necesidad de construir categorías inclusivas de los componentes sobre los cuales se construye el consenso, esta necesidad nos llevó a construir 6 categorias para caracterizar la información obtenida en los trabajos de campo.

\section{a. Los actores sociales y su ac- tuación en el Campo Educativo}

La segunda dimensión analizada intenta dar cuenta de los mecanismos de inclusión, condicionamientos y exclusión de actores participantes en esta arena de política. La relevancia de esta dimensión se basa en que históricamente el desarrollo del sistema educativo se conformó con la inclusión creciente, más aún en la particular forma que adquirió la forma bienestarista de estado en la Argentina.

La ampliación de actores en el campo fue un factor facilitador de la expansión educativa, cobrando fuerte relevancia la actuación de actores sindicales, la iglesia y las familias a través de las cooperadoras escolares. Este protagonismo es obturado desde los cambios en curso, justificados desde distintos argumentos. La desmovilización de los actores cumple

14 Pierre Bourdieu ha realizado aportes de gran valor sobre la forma de comprensión y acción de los agentes sociales sobre el mundo objetivado. En su obra "La Reproducción" de 1970 ya desarrolla el concepto de violencia simbólica, pero hemos extraído su concepcíón de una recopilación de Seminarios dados en Chicago en 1987. Al respecto continuamos la cita anterior "Llamo desconocimiento al hecho de desconocer una violencia que se ejerce, precisamente en la medida en que se le desconozca como violencia; de aceptar este conjunto de premisas fundamentales, prereflexivas, que los agentes confirman al considerar al mundo como autoevidente, es decir, tal como es, y encontrarlo natural porque le aplican estructuras cognoscitivas surgidas de las estructuras mismas de dicho mundo... por esta razón el anallsis de la aceptación dóxica del mundo, que resulta del acuerdo inmediato de las estructuras objetivas con las estructuras cognoscitivas es el verdadero fundamento de una teoría de la Dominación y de la Política. De todas las formas de "persuasión clandestina", la más implacable es la ejercida simplemente por el orden de las cosas. (Bourdieu y WacQuant, 1995)."Proponerse pensar el Estado significa exponerse a retomar por cuenta propia, un pensamiento de Estado. A aplicar al Estado unas categorias de pensamiento producidas y avaladas por el Estado, por lo tanto, a no reconocer la verdad más fundamental de éste...se acepta volver a este punto de partida, pero armado con el conocimiento de uno de los poderes más importantes del Estado, el de producir y de imponer (en particular mediante la escuela) las categorías de pensamiento que aplicamos a todo lo que en el mundo hay, y al propio Estado." (Bourdieu, 1997). 
dos objetivos, uno político, que consiste en disminuir los condicionamientos a la gestión gubernamental por la presión de acuerdos neocorporativos; otro económico y vinculado estrechamente al anterior, por cuanto el protagonismo de los actores contribuyó continuamente a la expansión del gasto.

De las expresiones en torno a la categoria de percepción sobre la participación de los actores del campo educativo, surge una clara identificación de cambio de escenario y de luchas al interior del campo.

La conformación del campo actual se presenta con una disminución del protagonismo de las entidades sindicales y el surgimiento de otros actores agregados como las ONGs, que disputan la capacidad de interlocución con el gobierno y la representación de intereses sectoriales.

En segundo lugar, se observa una disminución de la potencia de los actores tradicionales del campo merced a su baja capacidad de movilización que se inscribe dentro del contexto general de desmovilización de los sectores trabajadores tanto por las politicas de flexibilización laboral y ajuste del sector público, como de una nueva representación sobre la ineficacia de la movilización como recurso para obtener respuestas a demandas.

En tercer lugar, la posibilidad de acciones en conjunto entre los actores del campo, se restringe a cuestiones puntua- les y coyunturales. Aparecen sintomas de desconfianza y descrédito entre los actores, lo cual conlleva una pérdida de solidaridad entre los mismos.

Este último proceso se agudiza y toma especial carácter en la puja distributiva. Resulta reiterativa el antagonismo manifiesto entre los representantes de los sectores medios y entre los nuevos pobres. Por otra lado hay antagonismos entre pobres estructurales y nuevos pobres. Mientras el primer antagonismo se expresa en la arena de los actores sociales agregados, el segundo se manifiesta en la lucha por la posibilidad de utilización del servicio, en los establecimientos.

\section{b. Educación, Oportunidades Sociales y Economía ${ }^{15}$}

El servicio educativo cumplió una función de ampliador de las oportunidades de inclusión social, base ideológica del campo educativo que existe desde sus orígenes en 1880 . Sobre esta función es que actualmente hay tensiones entre oferta y demanda. Por ello hemos considerado que la educación como facilitador de oportunidades sociales es una primera categoría en la cual se puede observar si hay cambios en el consenso.

Del conjunto de las expresiones observadas en los trabajos de campo, se observa un primer elemento en común, claramente se identifican los cambios que están ocurriendo como cambios de la forma estatal bienestarista, en este senti-

15 La categoría intenta dar cuenta de las percepciones de los actores sobre los distintos elementos que hacen al financiamiento de la educación. Históricamente la representación fijaba al financiamiento educativo como una tarea que debía ser asumida por el estado, sostenía la gratuidad de la escuela pública y también el acceso a la escuela privada. 
do se valora la educación por su función "Educativa" y no por su capacidad de generar o mejorar oportunidades sociales.

Como tendencia el conjunto de los actores percibe una imposibilidad del estado de sostener el conjunto de aspectos que hacen al financiamiento educativo.

Pero cabe señalar que mientras desde la perspectiva oficial, estas restricciones objetivas del financiamiento no constituyen una imposibilidad de sostener niveles de garantía de los servicios, el desfinanciamiento es percibido por los usuarios como una pérdida de la prestación. Ante ello la alternativa del voluntarismo es claramente objetada, aunque vista como una complementariedad inevitable.

Los actores vinculados al consumo del servicio perciben como inevitable el desplazamiento de la responsabilidad estatal hacia la sociedad, hecho que sin dejar de ser resistido, los moviliza a asumirlo para mantener las prestaciones básicas. Estas nuevas actuaciones incorporan en si una nueva representación sobre los condicionamientos actuales a la gratuidad de la educación. El rol de la comu- nidad educativa en la escuela está cambiando desde la participación en las actividades escolares propiamente dichas hacia actividades de apoyo a la gestión escolar.

\section{c. Productividad, Calidad Educa- tiva $^{16}$ y Responsabilidad Estatal ${ }^{17}$ \\ En primer lugar, del discurso de los} actores se desprende una insuficiente identificación de la calidad educativa, denota una falta de comprensión de los componentes de la capacidad institucional para la prestación del servicio. Por otro lado, la productividad está vinculada solamente al tamaño y costos del servicio, quedando fuera los resultados del servicio.

La tendencia más importante que se asume como inevitable es aquella que reconoce una limitación de la responsabilidad estatal. Desde la necesidad de abandono de una visión binestarista pro. tectora hasta aquella que reconoce una focalización de la intervención en los sectores más carenciados.

Dentro de esta tendencia, resulta un planteamiento común la delegación de la misión estatal en la sociedad, aunque

16 La percepción sobre la productividad (relación entre costos y resultados) y calidad (relación entre eficacia y efectividad) del servicio resulta tal vez una de las categorias que más refleja las visiones que están en juego, en torno a la definición de un nuevo consenso en el campo educativo. En cierta forma constituiria a nivel representacional los limites de una transacción, mediante la cual se aceptan progresivamente las restricciones en la variedad y tipo de oferta a cambio de mantener un piso de calidad del servicio. Por otro lado, la calidad educativa es ofrecida desde el nivel oficial como el nuevo objetivo de la reforma y que para lograrlo necesita de reconversiones en la oferta (racionalización de coberturas y administrativo-organizacional).

17 Esta categoría refiere al conjunto de representaciones en base a las cuales los actores visualizan el rol del estado. Consideramos a este categoría como central en tanto define las nuevas posiciones sobre la forma estatal post-bienestarista. Las creencias al respecto definen los límites y posibilidades de la intervención estatal ya sea resistiendo a los cambios 0 aceptando la retracción estatal. 
rescatando su función reguladora. Por otro lado, se identifican los cambios en la prestación directa del servicio por parte del estado, como así también los cambios en los mecanismos de financiamiento por parte del este. En ambos casos, hay una representación de retracción estatal, tanto por la reorganización de las prestaciones como por los progresivos condicionamientos en el financiamiento.

\section{d. El Derecho al acceso Educa- tivo $^{18}$ \\ El acentuamiento de criterios de} equidad como mecanismo para hacer frente a los inevitables ajustes del sistema educativo, vía selectividad y focalización, introducen una distorsión que lleva a una redefinción del concepto de ciudadanía. La misma se produce porque la equidad refiere a un relación de reciprocidad entre necesidades técnicamente evaluadas y la oferta del servicio, con lo cual la dimensión política de la definición de necesidad queda subsumida en una valoración técnica. Desde esta perspectiva, los derechos ciudadanos al acceso educativo son definidos técnicamente como estratificados.
Esta restricción del ejercicio ciudadano (ciudadanía de baja intensidad), es claramente percibida como uno de los componentes tanto de la desmovilización social como de la exclusión y visto como una pérdida del potencial de inclusión tanto para la generación presente como para las futuras.

\section{A modo de Conclusiones}

Tal vez el interés que nos motivó en estos estudios tiene íntima relación con nuestra pertenencia al sistema educativo y en esta perspectiva es que no suponemos la objetividad de este trabajo introductorio, sino lo contrario, nos interesa la subjetividad que subyace al mismo.

Nuestra tarea de investigadores implicó que la pre-ocupación por los cambios en el campo educativo se manifestara en una ocupación de estudiar un problema central para ayudarnos a entender estos cambios, y nos formulamos la pregunta: cómo son aceptados los mismos? Hemos partido de una idea poco fundada sobre la negatividad de los cambios, configurándolos como pérdida,

18 Esta categoría responde a una construcción histórico-social que vincula la condición de ciudadanía con derechos plenos al acceso educativo. La percepción sobre este aspecto estaria reflejando el impacto de estos cambios sobre las posibilidades de inclusión política y social del sistema educativo en nuestras sociedades. Como ha sido señalado más arriba y en oposición a los planteamientos realizados en los países centrales, la educación habría constituido en nuestro pais un sistema con fuertes capacidades para sostener niveles de inclusión que contrarrestaron las inequidades del sistema económico. Esta función de mejorar las condiciones de igualdad y equidad en relación a la inclusión social, que la escuela cumplió desde fines de siglo pasado, actualmente está en entredicho, sobre todo el componente igualitario. 
restricción o retracción, pero en todos los casos como un efecto de la disminución general de los derechos ciudadanos. Nuestro lugar como investigadores y docentes universitarios nos llevó necesariamente a un posicionamiento defensivo de lo existente como propio de un mundo conocido y a ser defendido. Una expresión de la acción defensiva son los resultados de las investigaciones, se podría decir que "los investigadores hablan por sus investigaciones". Sin embargo los trabajos de campo nos contrastaron algunos supuestos, el registro poblacional mayoriatrio de la misma idea de pérdida no opera en lo cotidiano sino como hecho extraordinario, por lo cual los cambios se "naturalizan" y una mayor "organización" de lo poco disponible es percibido positivamente.

También pudimos tomar "contacto" con el poder performativo del discurso político y sobre todo con el poder "Formativo" del discurso técnico. Tanto entre los dirigentes políticos, funcionarios politicos, gremialistas, prestadores del servicio educativo y comunidad educativa en general el discurso técnico contiene una carga de "verdad" incontrastable. De alli que la visión fatalista ante la necesidad de "reducir" los gastos es una verdad y la adaptación ante la misma es utilizar mejor "lo que hay o lo queda". Se podría afirmar que la reconfiguración de los servicios propios del estado bienestarista, como la educación, son percibidos en forma de "residuo" o "remanente" de otras épocas de mayor esplendor, desde esta visión es que su accesibilidad es doblemente cuestionada.

La accesibilidad como antes lo fue ha desaparecido, hay un nuevo acceso condicionado por el tiempo, no se sabe cuanto durará? Por otro lado, para qué sirve? Esta doble incertidumbre del sistema educativo tiene una fuerte explicación en la retracción del mercado laboral y su refractariedad actual a ser impactado por el sistema educativo, sin embargo nos hemos preguntado qué otros aspectos antropológicos operan en el consumo del servicio educativo, tal vez la pregunta no sea, por qué hay tanta deserción o desgranamiento en el sistema educativo, sino por qué sigue habiendo tanta demanda? Sobre todo al considerar la fuerte desvalorización cultural a que está siendo sometida la escuela, su rol trascendente en la sociedad está pasando a ser un anacronismo.

Creemos que estos interrogantes superan ampliamente nuestro campo de trabajo, centrado en las nuevas configuraciones estatales y de los servicios públicos, sin embargo su respuesta es básica para inteligir la contradicción entre gran demanda poblacional por educación y la decepción constante ante los resultados de la misma.

\section{Bibliografía citada}

Bobbio Norberto y otros (1996), "Diccionario de Política", Séptima edición en español. Siglo XXI Editores. Buenos Aires.

Bolyvinik Jullo (1990). "Pobreza y Necesidades Básicas, conceptos y métodos de medición" Programa de las Nacio. nes Unidas para el desarrollo, Mimeo. Bogotá.

Bourdieu Pierre (1997). "Espiritus de Estado. Génesis y Estructura del Campo Burocrático" en "Razones Prácticas, sobre la teoría de la acción". Editorial Anagrama. Barcelona. 
Bourdieu, Pierre y Loic J. D. WacQuant (1995). "Respuestas, por una Antropologia refiexiva", editorial Grijalbo, México.

Carrizo Cecilia, Santiago Graciela y Halaban Jorge (1994). "Un Análisis de Política: el caso de la Educación Municipal en la Ciudad de Córdoba, 1983,1990" Tesis de maestria en Administración Pública, Volumen 1 , publicado por el Instituto de Investigación y Formación en Administración Pública, Córdoba.

Castel, Robert (1998). "La Metamorfosis de la Cuestión social, una crónica del salariado". Editorial Paidós Buenos aires.

Claus Offe (1995). "Un diseño no productivista para las Politicas Sociales" en Lo Vuolo Rubén (Compilador) "Contra la Exclusión: La propuesta del ingreso ciudadano" CIEPP, Miño y Dávila Editores, Buenos Aires.

Ewen Stuart (1996). "Todas las imágenes del consumismo" Editorial Grijalbo, México.

Girod, Roger (1984). "Política Educativa. Lo llusorio y lo posible" Editorial Kapelusz, Buenos Aires.

Grassi Estela, Hintze Susana y Neufeld María Rosa (1994). "Crisis Y Ajuste Estructural" Espacio Editorial, Buenos Aires.

Katz Jorge (1989). "Salud : puja distributiva y equidad" Editorial Centro Editor de América Latina. Buenos Aires.

Kessler Gabriel y Alberto Minujin (1995). "La nueva pobreza en Argentina" Edit. Planeta. Buenos Aires.

La Serna Carlos y Tecco Claudio (1991). "Gestión Urbana en Ciudades Intermedias Seleccionadas de América Latina"; Proyecto ONU/CEPAL Córdoba. Argentina.

La Serna Carlos, Ahumada Jorge y Burijovich Jacinta (1996). "Oferta y demanda de Politicas Sociales: racionalidad esta- tal y estrategias de consumo" Reforma y Democracia Nro. 6, Revista del CLAD, Venezuela.

La Serna Carlos (1997). "Actores y Procesos en la Crisis del Estado de Bienestar" Administración Pública y Sociedad, No. 10, Córdoba.

Lo Vuolo R. y Barbeito A. (1992). "La Modernización Excluyente" UNICEF-CIEPP. Losada, Buenos Aires.

Lo Vuolo Rubén y Barbeito Alberto (1994). "La Nueva Oscuridad de la Política Social" Miño y Dávila Editores, Buenos Aires.

Marquez Angel Diego (1995). "La Quiebra del Sistema Educativo Argentino: Política Educacional del Neoconservadurismo "Libros del Quirquincho, Buenos Aires.

Minujin Alberto (editor) (1993). "Desigualdad y Exclusión" UNICEF- Losada, Buenos Aires.

Nassif, R, Rama, G. y Tedesco, J.C. (1986). "El Sistema educativo en América Latina" edit. Kapelusz, Buenos Aires.

Navarro Mario (1995). "Democracia y Reformas Estructurales: Explicaciones de la tolerancia popular al ajuste económico" Desarrollo Económico Revista de Ciencias Sociales, vol. 35, No. 139 Buenos Aires. OctubreDiciembre.

O'Donnell Guillermo (1997). "Estado y alianzas en la Argentina, 1956-1976" incluido en la selección de textos del mismo autor "Contrapuntos: ensayos escogidos sobre autoritarismo y democratización". Editorial Paidos. Buenos Aires.

Offe Claus (1990). "Contradicciones en el Estado del Bienestar", Alianza Editorial. México

Offe Claus (1992)."La Sociedad del Trabajo" Alianza Editorial, Madrid. 
Paiva Vanilda (1992). "Educación Bienestar Social y Trabajo", Libros del Quirquincho, Buenos Aires.

Parra, Rodrigo et al (1986). "La educación popular en América Latina". Editorial Kapelusz, Buenos Aires.

Paviglianiti Norma (1991). "Neoconservadurismo y Educación, un debate silenciado en la Argentina del 90". Libros del Quirquincho, Buenos Aires.

Rama Germán (1986). "Educación, Participación y Estilos de Desarrollo en América Latina" CEPAL-KAPELUSZ, Buenos Aires.

Rama Germán et al (1987). "Desarrollo y Educación en América latina y el Caribe" CEPAL,UNESCO,PNUD Edit. Kapelusz, Buenos Aires.

Rama, Germán (1994). "Educación y cambios en la estructura social en América Latina" Revista Proyecto Principal de Educación en América Latina y el Caribe. Nro. 35, UNESCO, OREALC, Chile. Diciembre.

Rama, Germán (1994). "Necesidades de información para la toma de decisiones en una gestión moderna de los Ministerios de Educación" revista del Proyecto Principal de Educación en América
Latina y el Caribe Nro. 33, UNESCO, OREALC. Chile, Abril.

Sen Amartya (1996). "Pobres relativamente hablando" Resources, valius and development. Edit. Basil Blackwell Londres, 1984 (traducción para el Seminario Iberoamericano de desarrollo de profesores en gerencia social, CLAD, Buenos Aires).

Tedesco Juan Carlos (1987). "El desafío educativo: calidad y democracia". Grupo Editor Latinoamericano, Buenos Aires.

Tedesco Juan Carlos (1986). "Educación y sociedad en Argentina (1880-1945)" Ediciones Solar. Buenos Aires.

Tedesco, Juan Carlos (1986). "Conceptos de Sociologia de la Educación". Centro Editor de América Latina, Buenos Aires.

Tenti Fanfani Emilio (1989). "El Estado Educador" en Isuani E. Estado Democrático y Política Social. EUDEBA. Buenos Aires.

Torres Alberto Torres et al (1994). "Sociologia de la Educación: corriente contemporáneas" Miño y Dávila Editores, Buenos Aires. 